\title{
THE INFLUENCE OF DRUGS ON THE RESPONSE OF A CELL CULTURE PREPARATION TO BACTERIAL TOXINS
}

\author{
*L. G. Giugliano and B. S. Drasar
}

\section{Department of Medical Microbiology, London School of Hygiene and Tropical Medicine, Keppel Street, London WCIE $7 H T$}

\begin{abstract}
SUmmary. The influence was studied of lanthanum chloride, chlorpromazine hydrochloride, indomethacin and sodium cromoglycate on the morphological changes induced in Vero cells by the action of the cholera toxin, the thermolabile enterotoxin (LT) and the Vero cell cytotoxin (VT) of Escherichia coli, the enterotoxin of Clostridium perfringens, and the cytotoxin of Clostridium difficile. These drugs were able to inhibit the effects produced by $C$. difficile cytotoxin but not by the other toxins examined.
\end{abstract}

\section{INTRODUCTION}

Recent studies of the pharmacological interruption of the secretory effects of cholera toxin and of the heat-labile (LT) and heat-stable (ST) enterotoxins of Escherichia coli have shown that drugs such as chlorpromazine, lanthanum chloride, indomethacin and sodium cromoglycate (cromolyn) inhibit the effects induced by these toxins in vivo.

Investigation of the mechanism of cholera toxin has led to a better understanding of the process of active secretion in the intestine. Cyclic nucleotides are important intracellular mediators of the action of intestinal secretogogues, such as cholera toxin, the ST and LT enterotoxins of E. coli, Vasoactive Intestinal Peptide, prostaglandins, and bile acids (Rask-Madsen and Bukhave, 1981; Turnberg, 1981). Cholera toxin, the ST and LT enterotoxins of $E$. coli and certain prostaglandins have been shown to stimulate intestinal fluid secretion in vivo and to activate intestinal mucosal adenylate or guanylate cyclase (Kimberg et al., 1971; Evans et al., 1972; Finkelstein, 1973; Hughes et al., 1978).

Other recent evidence indicates that calcium and the intracellular calcium-binding protein calmodulin play a crucial role in stimulating intestinal secretion. This conclusion was based primarily on the observation that the calcium ionophore A23187 induces intestinal secretion (Bolton and Field, 1977; Frizzell, 1977) and that trifluorperazine, an inhibitor of the formation of the calcium-calmodulin complex, inhibits this effect. Furthermore, trifluorperazine inhibits the changes in electrolyte

Received 9 May 1983; revised version accepted 20 Aug. 1983. Brazil.

* Present address: Instituto Nacionale de Pesquitas de Amazonia, Estrada do Aleixo 1756, Manaus, 
transport caused by those secretogogues that act through cyclic nucleotides and this suggests that calcium is involved in CAMP- and cGMP-induced intestinal secretion (Ilundain and Naftalin, 1979; Smith and Field, 1980).

As several phases of toxin-stimulated secretion can now be distinguished, the present study seeks to exploit drugs that inhibit different stages in the secretory process to elucidate mechanisms of toxin action. Most of the studies of the influence of drugs on the action of toxins have been performed with animal models. In the present study, we have examined the influence of drugs on cell-toxin interaction with special reference to the action of enterotoxins. Vero cells were used in these studies because they are sensitive to a wide range of toxins including cholera toxin, the LT enterotoxin and Vero cell cytotoxin (VT) of $E$. coli, Clostridium difficile cytotoxin and $C$. perfringens enterotoxin.

\section{Materials AND Methods}

Drugs. Lanthanum chloride $\left(\mathrm{LaCl}_{3} \cdot 7 \mathrm{H}_{2} \mathrm{O}\right.$; Sigma L4131), chlorpromazine hydrochloride (CRP; Sigma), indomethacin (IND; donated by Merck, Sharp and Dohme Research Laboratories) and sodium cromoglycate (CRM; donated by Fisons PLC, Pharmaceutical Divisions) were used. Seven two-fold serial dilutions of the drugs were prepared in $50 \mathrm{~mm}$ TRIS-HCl, $p \mathrm{H} 7 \cdot 0$ (TRIS-hydroxymethyl methylamine, BDH Chemicals Ltd, Poole). Initial concentrations of CRM, CRP and IND were $44 \mu \mathrm{g} / \mathrm{ml}$ and that of $\mathrm{LaCl}_{3} 462 \mu \mathrm{g} / \mathrm{ml} ; 25-\mu \mathrm{l}$ volumes of each of the drugs in each of the dilutions were added to the wells of microtitration plates (Falcon, Microtest II, Becton Dickinson and Co., Cockeysville, MD, USA) containing 25 $\mu \mathrm{l}$ each of the 10 two-fold serial dilutions of the toxin under test. Drugs were tested singly and in combination.

Toxin preparations. E. coli strains $\mathrm{H} 296$ and $\mathrm{H} 19$ were used for the production of LT and VT toxins respectively, as described by Giugliano, Mann and Drasar (1982). A cytotoxin-producing strain of $C$. difficile (HA) donated by Dr P. Borriello, Clinical Research Centre, Harrow Road, London, was used for the production of cytotoxic culture filtrates as described by Larson et al. (1978). Purified $C$. perfringens type A enterotoxin $(5 \mathrm{mg} / \mathrm{ml})$ was provided by $\mathrm{Dr} \mathrm{R}$. Skjelkvale (Norwegian Food Research Institute, Oslo, Norway). A purified preparation of cholera toxin obtained from Sigma was used at an initial dilution of $0.5 \mu \mathrm{g} / \mathrm{ml}$.

Tissue culture assay. The influence of the drugs on the action of the bacterial toxins was assayed with cultures of African Green monkey kidney (Vero) cells. The procedures for maintenance and toxin assay were described by Giugliano et al. (1982). Briefly, the mixtures of the drugs and bacterial toxin dilutions were added to freshly seeded cells in microtitration plates and incubated at $37^{\circ} \mathrm{C}$. Cells were examined microscopically after incubation for 18-20, 48 and $72 \mathrm{~h}$ at $37^{\circ} \mathrm{C}$. Any observed effect on cell growth and morphology was scored in arbitrary units: $0,1,2,3$ and 4 corresponded respectively to $0,25,50,75$ and $>90 \%$ cells with abnormal appearances. The titre of the toxin was taken as the highest dilution that gave a $50 \%$ end-point, calculated, if necessary, by interpolation.

\section{RESULTS}

The effects of lanthanum chloride $\left(\mathrm{LaCl}_{3}\right)$, chlorpromazine (CRP), indomethacin (IND) and sodium cromoglycate (CRM) on the response of Vero cells to the toxins were studied in cell-culture preparations.

None of the drugs showed any influence on the activity of the filtrates of LT-producing or VT-producing $E$. coli, purified enterotoxin of $C$. perfringens or cholera enterotoxin. However, the drugs inhibited the effect produced on the cells by filtrates of $C$. difficile. Figs 1 and 2 show the percentage of cells affected in the presence of several concentrations of CRP and $\mathrm{LaCl}_{3}$ and diluted filtrates of a cytotoxigenic strain of $C$. difficile. Both drugs inhibited the $C$. difficile cytotoxin, and the effect was 


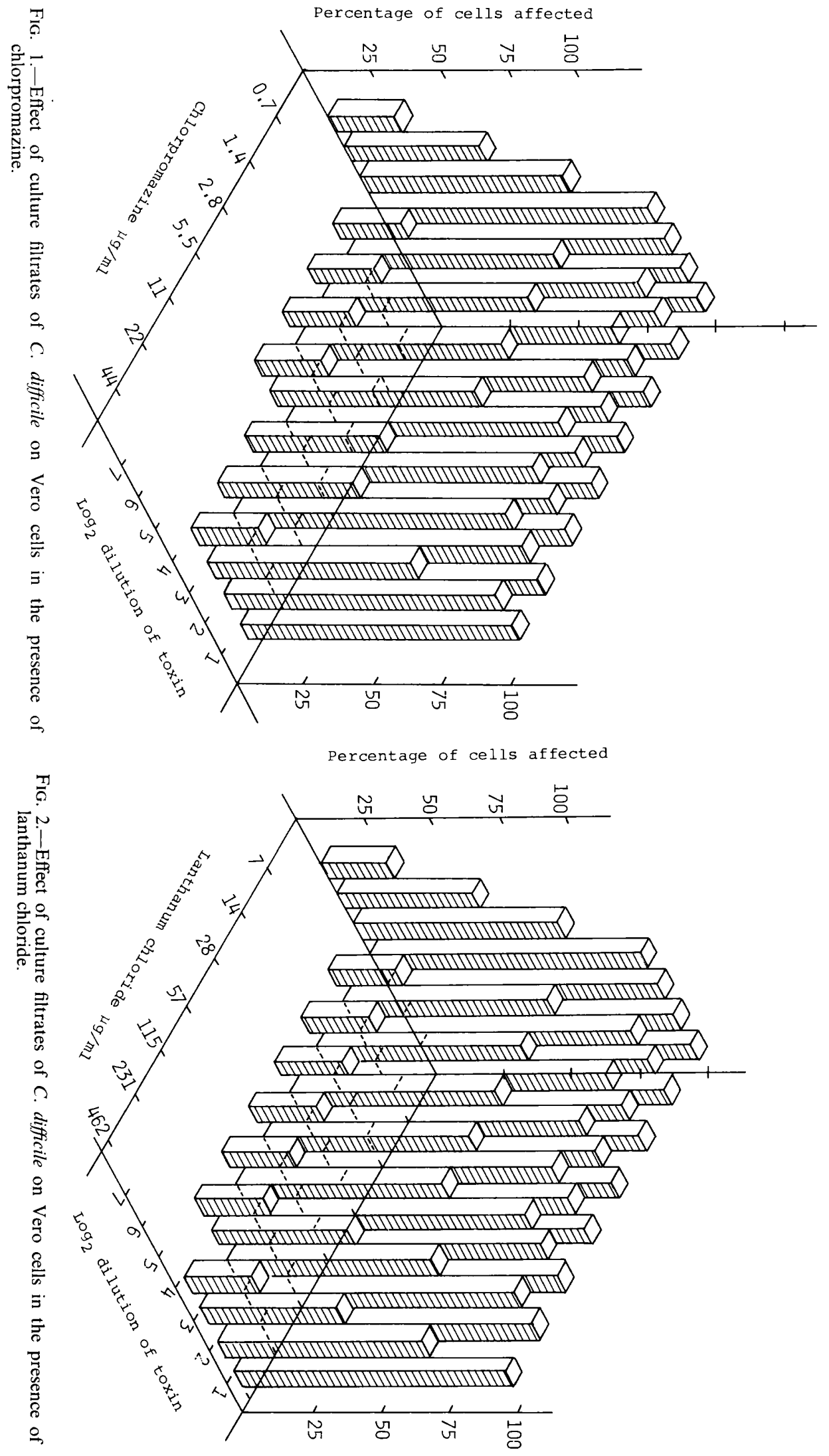




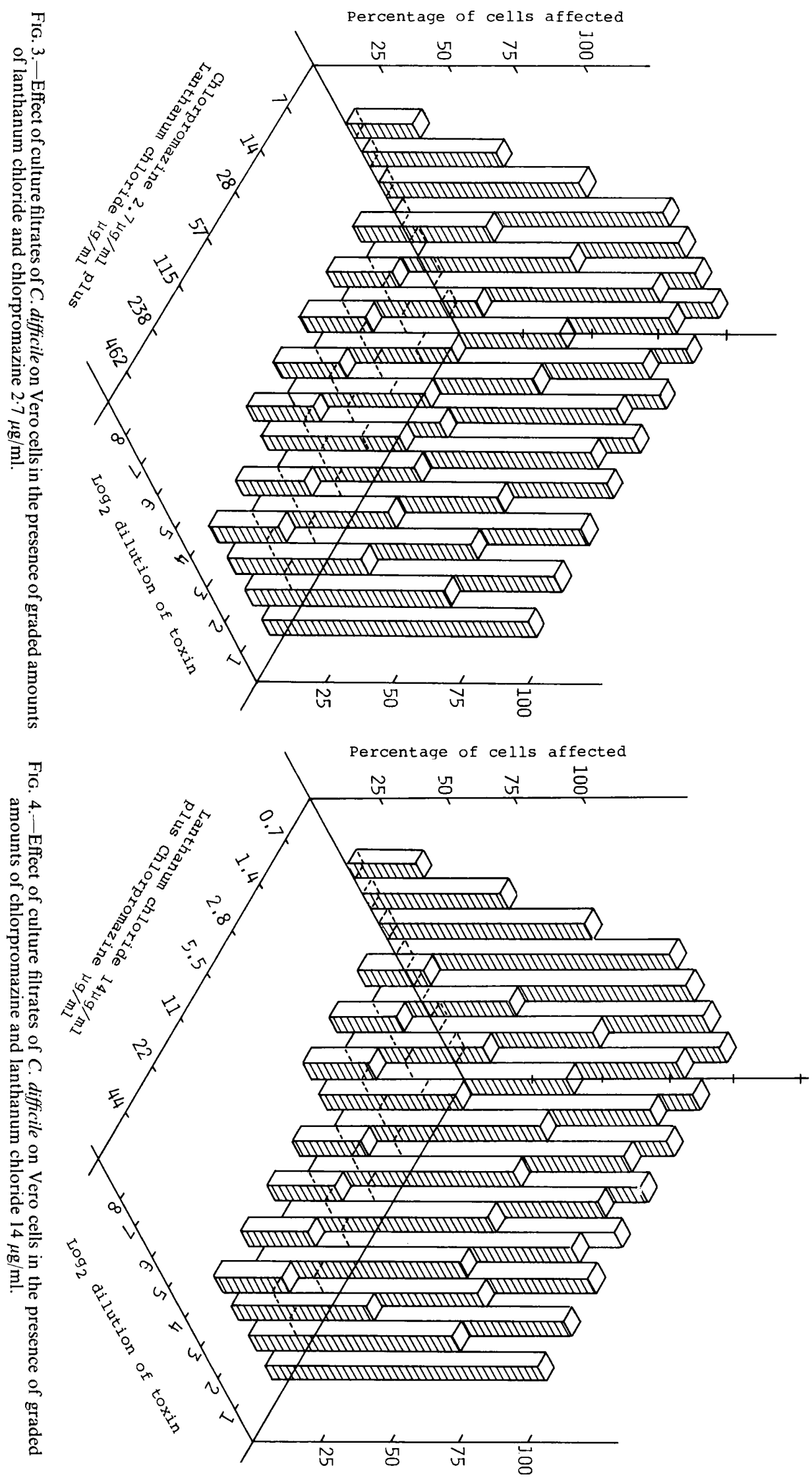


dose-related. Indomethacin and CRM also inhibited the effect of $C$. difficile filtrates, but the degree of inhibition was the same within the limits of the concentration of each of these drugs. There was some evidence that the inhibition of the effects of toxin was potentiated by combining the drugs. Thus, more effective protection was observed when CPR and $\mathrm{LaCl}_{3}$ were used together (Figs 3 and 4). It was not possible to test combinations of CRM and IND, or CRM and $\mathrm{LaCl}_{3}$, because precipitation of the mixtures occurred.

\section{DisCUSSION}

The effects of drugs on intestinal secretion may be explained by reference to their influence on the metabolism of cyclic nucleotides or of calcium and to interactions with prostaglandins (fig. 5). The action of the drugs used in this study has not been
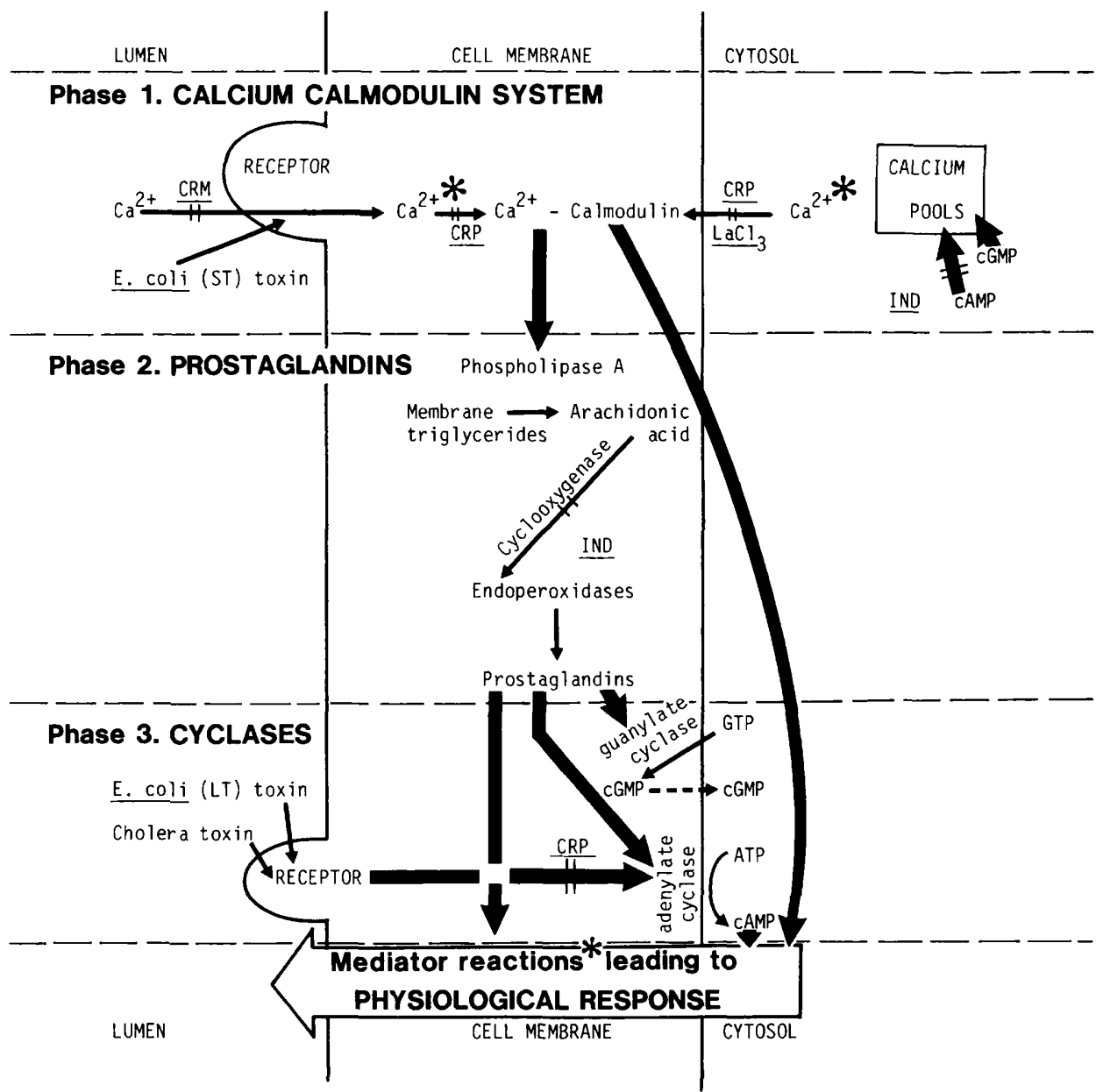

FIG. 5.- Outline of the secretory system stimulated by cholera toxin and the LT and ST enterotoxins of $E$. coli. The points of action of chlorpromazine (CRP), lanthanum chloride $\left(\mathrm{LaCl}_{3}\right)$, indomethacin (IND) and sodium cromoglycate (CRM) are marked. The possible sites of action of $C$. difficile toxins are indicated $(*)$. Key: Reactions $\rightarrow$, Interactions $\rightarrow$, Blocked reactions $\sharp$ and interactions $\sharp$. 
completely elucidated, but it is known that indomethacin (IND) acts as an inhibitor of cyclo-oxygenase and, therefore, of the synthesis of prostaglandins. IND has been shown to inhibit the secretion induced by cholera, and by the LT and ST enterotoxins of $E$. coli, but it does not affect the levels of cAMP or the toxin-induced activation of adenylate cyclase (Kimberg et al., 1971; Wald et al., 1977; Madsen and Knoop, 1978; Greenberg et al., 1980), although it does inhibit the activation of guanylate cyclase induced by ST (Greenberg et al., 1980).

Chlorpromazine (CRP) has a variety of properties, among them the binding of calmodulin (Wolff and Brostrom, 1979) and inhibition of secretion induced by cholera enterotoxin, the LT and ST enterotoxins of E. coli, and cGMP and cAMP analogues (Holmgren, Lange and Lonnroth, 1978; Abbey and Knoop, 1979; Greenberg et al., 1980). Furthermore, Holmgren et al. (1978) have shown that CRP reduces cholera toxin-mediated activation of adenylate cyclase and the secretion induced by cAMP analogues. Greenberg et al. (1980) have shown that this drug reduces ST-mediated activation of guanylate cyclase. Thus, CRP can influence both the production of cyclic nucleotides and their effects on membranes as mediated by the calcium-binding protein, calmodulin.

Lanthanum chloride $\left(\mathrm{LaCl}_{3}\right)$ has been shown to act as a calcium antagonist (Weiss, 1974 ) and to inhibit secretion caused by cholera toxin and E. coli LT and ST toxins. It seems to act in the reaction sequence beyond the formation of the cyclic nucleotides. The accumulation of CAMP and the activation of guanylate cyclase by cholera and ST toxins respectively were not reduced by $\mathrm{LaCl}_{3}$. Furthermore, it has been shown to inhibit secretion caused by cGMP analogues (Leitch and Amer, 1975; Greenberg, Murad and Guerrant, 1982). Sodium cromoglycate (CRM) inhibits calcium ion uptake and ST-induced secretion caused by cGMP analogues (Thomas and Knoop, 1982).

The sites of action of the drugs used in this study on mechanisms of secretion stimulated by cholera toxin and the ST and LT toxins of E. coli are shown in outline in fig. 5. For clarity the secretory mechanisms are divided into three phases: (i) the calcium-calmodulin system; (ii) prostaglandins; (iii) guanylate and adenylate cyclase. That none of the drugs used in this study affected the responses of the cells to cholera toxin or to the LT enterotoxin of $E$. coli suggests that the accumulation of cAMP necessary to induce morphological changes in cells was not impaired by the drugs. These results support the findings of Kimberg et al. (1974) and Leitch and Amer (1975) who showed that $\mathrm{LaCl}_{3}$ and IND did not affect the levels of cAMP induced by cholera and LT toxins on intestinal mucosa. Furthermore, Holmgren et al. (1978) have shown that CRP inhibits the secretion of intestinal fluid mediated by dibutyryl cAMP. This indicates that the primary action of CRP may be at a stage subsequent to the formation of cAMP in the secretory pathway and that the inhibition of toxin-dependent stimulation of adenylate cyclase is unimportant in Vero cells. Because $\mathrm{LaCl}_{3}, \mathrm{CRP}$, CRM and IND can inhibit calcium-dependent cellular events and cholera and $E$. coli enterotoxin-induced intestinal secretion, it has been assumed that calcium has an important role in the action of these toxins. The lack of influence of these drugs on the induction of morphological changes in cells in culture may indicate that calcium metabolism is not involved in the typical morphological changes of the cells in culture produced in response to cholera and LT enterotoxins.

The VT cytotoxin of $E$. coli does not stimulate adenylate cyclase, and cAMP is 
probably not involved (Konowalchuck et al., 1978). The results of the present study do not provide further clues as to the mechanism of its action.

The mechanism of action of $C$. perfringens enterotoxin is largely unknown. However, it has been shown that its mode of action is different from that of cholera enterotoxin and the LT enterotoxin of $E$. coli. Levels of cAMP are not affected but glucose absorption by the intestinal mucosa is inhibited (McDonel, 1974 and 1979). Furthermore, the results of work by McDonel and Duncan (1977) on the effect of $C$. perfringens enterotoxin on mitochondrial respiration suggested that alterations in electrolyte transport could be caused by a reduction in the energy supply available to the cell. Because none of the drugs used in this study inhibited the effect of $C$. perfringens enterotoxin on cells, it is likely that neither cyclic nucleotides nor calcium is involved in its action. This possibility was considered by $\mathrm{McDonel}$ and Duncan (1977). Alternatively, the action of the drugs in the reaction sequence may occur only after the main metabolic event responsible for the morphological changes observed on the cells. This seems to be the case with cholera and LT enterotoxins.

The mechanism of action of $C$. difficile on the intestinal mucosa is not well understood but at least two toxins, the cytotoxin and the enterotoxin, are involved. The enterotoxin is only slightly cytotoxic. C. difficile also produces several other extracellular products. The filtrates used in the present study contained various products and the effects observed may result from their combined action.

The effect of $C$. difficile toxins on cells in culture was inhibited by all of the drugs used, and the combination of $\mathrm{LaCl}_{3}$ and CRP produced a greater inhibition of the toxin-induced effect than either of the drugs alone. These results indicate that calcium-dependent cellular events were involved in the induction of morphological changes in the cells. Enhancement of inhibition by combining $\mathrm{LaCl}_{3}$ and $\mathrm{CRP}$ has been reported for cGMP-mediated ST enterotoxin-induced secretion in infant mice. Whilst the mechanism of action of $C$. difficile toxin remains unclear, the studies of Hughes et al. (1983) on $C$. difficile toxin-induced secretion in rabbit ileum in vitro provided evidence that cyclic nucleotides are not involved but that calcium may play an important role in the activity of toxin. Thus, the $C$. difficile toxins may influence the activation of the calcium-calmodulin complex or act at some subsequent point of the pathway leading to the final cellular response. The response would in any case be dependent on the presence of activated calcium-calmodulin complex, and the inhibition of the effects of $C$. difficile toxin by cromoglycate indicates that calcium influx plays a significant role in the cell response to the toxin (fig. 5).

\section{REFERENCES}

Abbey D M, Knoop F C 1979 Effect of chlorpromazine on the secretory activity of Escherichia coli heat-stable enterotoxin. Infection and Immunity 26:1000-1003.

Bolton J E, Field M 1977 Ca ionophore-stimulated ion secretion in rabbit ileal mucosa: relation to actions of cyclic $3^{\prime} 5^{\prime}$ AMP and carbamylcholine. Journal of Membrane Biology 35:159-173.

Evans D J, Chen L C, Curlin G T, Evans D G 1972 Stimulation of adenylcyclase by Escherichia coli enterotoxin. Nature New Biology 236:137-138.

Finkelstein R A 1973 Cholera. Critical Reviews of Microbiology 2:553-623.

Frizzell R A 1977 Active chloride secretion in rabbit colon: calcium dependent stimulation by ionophore A23187. Journal of Membrane Biology 35:175-187.

Greenberg R N, Murad F, Chang B, Robertson D C, Guerrant R L 1980 Inhibition of 
Escherichia coli heat-stable enterotoxin by indomethacin and chlorpromazine. Infection and Immunity 29:908-913.

Greenberg R N, Murad F, Geurrant R L 1982 Lanthanum chloride inhibition of the secretory response to Escherichia coli heat-stable enterotoxin. Infection and Immunity 35:483-488.

Guigliano L G, Mann G F, Drasar B S 1982 Response of mammalian cell lines to the toxins of Escherichia coli. Journal of Medical Microbiology 15:531-539.

Holmgren J, Lange S, Lonnroth I 1978 Reversal of cyclic AMP mediated intestinal secretion in mice by chlorpromazine. Gastroenterology 75:1103-1108.

Hughes J M, Murad F, Chang B, Guerrant R L 1978 Role of cyclic GMP in the action of heat-stable enterotoxin of Escherichia coli. Nature 271:755-756.

Hughes S, Warhurst G, Turnberg L A, Higgs N B, Giugliano L G, Drasar B S 1983 Clostridium difficile toxin-induced intestinal secretion in rabbit ileum in vitro. Gut 24:94-98.

Ilundain A, Naftalin R J 1979 Role of $\mathrm{Ca}^{2+}$-dependent regulator protein in intestinal secretion. Nature 279:446-448.

Kimberg D V, Field M, Johnson J, Henderson A, Gershon E 1971 Stimulation of intestinal mucosal adenyl cyclase by cholera enterotoxin and prostaglandins. Journal of Clinical Investigation 50:1218-1230.

Kimberg D V, Field M, Gershon E, Henderson A 1974 Effects of prostaglandins and cholera enterotoxin on intestinal mucosal cyclic AMP accumulation. Journal of Clinical Investigation 53:941-949.

Konowalchuck J, Dickie N, Stavric S, Speirs J L 1978 Properties of an Escherichia coli cytotoxin. Infection and Immunity 20:575-577.

Larson H E, Price A B, Honour P, Borriello S P 1978 Clostridium difficile and the aetiology of pseudomembranous colitis. Lancet 1:1063-1066.

Leitch G J, Amer M S 1975 Lanthanum inhibition of Vibrio cholerae and Escherichia coli enterotoxin-induced enterosorption and its effects on intestinal mucosa cyclic adenosine $3^{\prime}-5^{\prime}$ monophosphate and cyclic guanosine $3^{\prime}-5^{\prime}$ monophosphate levels. Infection and Immunity 11:1038-1044.

Madsen G L, Knoop F C 1978 Inhibition of the secretory activity of Escherichia coli heat-stable enterotoxin by indomethacin. Infection and Immunity 22:143-147.

McDonel J L 1974 In vivo effect of Clostridium perfringens enteropathogenic factors on the rat ileum. Infection and Immunity 10:1156-1162.

McDonel J L, Duncan C L 1977 Effect of Clostridium perfringens enterotoxin on mitochondrial respiration. Infection and Immunity 15:999-1001.

McDonel J L 1979 The molecular mode of action of Clostridium perfringens enterotoxin. American Journal of Clinical Nutrition 32:210-218.

Rask-Madsen J, Bukhave K 1981 The role of prostaglandins in diarrhoea. Clinical Research Reviews 1, Suppl 1 33-48.

Smith P L, Field M 1980 In vitro anti-secretory effects of trifluoperazine and other neuroleptics in rabbit and human small intestine. Gastroenterology 78:1545-1553.

Thomas D D, Knoop F C 1982 The effect of calcium and prostaglandin inhibitors on the intestinal fluid response to heat-stable enterotoxin of Escherichia coli. Journal of Infectious Diseases 145:141-147.

Turnberg L A 1981 Disturbances of intestinal ion transport in diarrhoea. Clinical Research Reviews 1, Suppl 1 1-9.

Wald A, Gotterer G S, Rajendra G R, Turjman N A, Hendrix T R 1977 Effect of indomethacin on cholera induced fluid movement unidirectional sodium fluxes, and intestinal cAMP. Gastroenterology 72:106-110.

Weiss G B 1974 Cellular pharmacology of lanthanum. Annual Review of Pharmacology 14: 343-354.

Wolff D J, Brostrom C O 1979 Properties and functions of the calcium-dependent regulator protein. Advances in Cyclic Nucleotide Research 11:27-88. 